\title{
Harmfulness of Fusarium crookwellense Burgess, Nelson \& Toussoun to panicles of selected genotypes of oat (Avena sativa L.) concerning the content of mycotoxins in grain
}

\section{Szkodliwość Fusarium crookwellense Burgess, Nelson \& Toussoun dla wiech wybranych genotypów owsa (Avena sativa L.) z uwzględnieniem zawartości mikotoksyn w ziarnie}

\author{
Elżbieta Mielniczuk $^{1 *}$, Irena Kiecana ${ }^{1}$, Małgorzata Cegiełko ${ }^{1}$, Alina Pastucha ${ }^{1}$, Juliusz Perkowski ${ }^{2}$
}

\begin{abstract}
Summary
The study was conducted on nine oat genotypes in the experimental plots in south-eastern part of Poland in the years 2014-2015. Oat panicles were inoculated with conidial suspension of Fusarium crookwellense no. 72 . The mean reduction in the number of grain per panicle compared to the control was $31.66 \%$ in 2014 and $21.52 \%$ in 2015 , while decrease in grain yield amounted to $38.96 \%$ and $21.76 \%$ respectively, and 1000 grain weight $12.72 \%$ and $6.02 \%$ respectively. The presence of nivalenol, deoxynivalenol, $3-A c$ DON and fusarenone $X$ was detected in grain of all oat genotypes. The mean concentration of these metabolites in the years 2014 and 2015 ranged respectively: 1.764 and $0.085 \mathrm{mg} / \mathrm{kg}, 0.050$ and $0.027 \mathrm{mg} / \mathrm{kg}, 0.017$ and $0.009 \mathrm{mg} / \mathrm{kg}$, and 0.066 and $0.024 \mathrm{mg} / \mathrm{kg}$. The presence of zearalenone was detected in the grain of some oat genotypes.
\end{abstract}

Key words: Fusarium crookwellense; fusariosis; mycotoxins; oat

\section{Streszczenie}

Badania przeprowadzono w latach 2014-2015, na polach doświadczalnych w południowo-wschodniej Polsce. Materiał infekcyjny stanowiła zawiesina konidiów Fusarium crookwellense nr 72. Średnia obniżka liczby ziarniaków w wiesze, w porównaniu do kontroli wynosiła w 2014 r. 31,66\%, zaś w 2015 r. 21,52\%, natomiast redukcja plonu ziarna wynosiła odpowiednio 38,96\% i 21,76\%, zaś obniżka masy 1000 ziaren odpowiednio 12,72\% i 6,02\%. W próbach ziarna wszystkich genotypów owsa stwierdzono obecność niwalenolu, deoksyniwalenolu, 3-Ac DON oraz fuzarenonu X, średnie stężenie tych metabolitów w latach 2014 i 2015 wynosiło odpowiednio: 1,764 i 0,085 mg/kg, 0,050 i 0,027 mg/kg, 0,017 i 0,009 mg/kg oraz 0,066 i 0,024 mg/kg. Ponadto w ziarnie niektórych genotypów owsa stwierdzono obecność zearalenonu.

Słowa kluczowe: Fusarium crookwellense; fuzarioza wiech; mikotoksyny; owies

\footnotetext{
Uniwersytet Przyrodniczy w Lublinie, Katedra Fitopatologii i Mykologii

Leszczyńskiego 7, 20-069 Lublin

${ }^{2}$ Uniwersytet Przyrodniczy w Poznaniu, Katedra Chemii

Wojska Polskiego 65, 60-625 Poznań

*corresponding author: elzbieta.mielniczuk@up.lublin.pl
} 


\section{Wstęp / Introduction}

Porażenie zbóż przez Fusarium spp. wiąże się z niebezpieczeństwem zanieczyszczenia ziarna mikotoksynami szkodliwymi dla organizmów stałocieplnych (Logrieco i wsp. 2003; Nielsen i wsp. 2011; Kiecana i wsp. 2012). W różnych rejonach uprawy fuzariozę wiech owsa powodują $F$. aveneceum, $F$. poae, $F$. langsethiae, $F$. culmorum i F. graminearum (Tekauz i wsp. 2004; Nielsen i wsp. 2011; Martinelli i wsp. 2014). W warunkach południowo-wschodniej Polski za główną przyczynę tej choroby uznano $F$. avenaceum i $F$. poae. Wśród innych gatunków $\mathrm{z}$ rodzaju Fusarium, na wiechach owsa w wymienionych warunkach uprawy stwierdzano obecność $F$. crookwellense (syn. F. cerealis) (Mielniczuk 2001; Kiecana i wsp. 2012). Gatunek ten został uznany za jedną z głównych przyczyn fuzariozy kłosów pszenicy ozimej uprawianej w Japonii (Sugiura i wsp. 1994), uzyskiwany był również z kłosów pszenicy w Kanadzie i Europie (Šrobarová i wsp. 2008; Amarasinghe i wsp. 2015) oraz z kłosów żyta i jęczmienia w Polsce (Kiecana 1994; Kiecana i Mielniczuk 2010), a także z ziarna jęczmienia w Argentynie i Chinach (Zhang i wsp. 2011; Castañares i wsp. 2013). F. crookwellense charakteryzuje się również znaczną szkodliwością dla liści i kolb kukurydzy uprawianej w Nowej Zelandii (Lauren i Di Menna 1999). Gatunek ten porażając ziarno, zanieczyszcza je szkodliwymi dla organizmów stałocieplnych mikotoksynami, takimi jak: niwalenol (NIV), deoksyniwalenol (DON) i jego acetylowe pochodne (3-Ac DON, 15-Ac DON), a także zearalenon (Perkowski i Kiecana 1998; Mielniczuk i wsp. 2004; Christ i wsp. 2011; Amarasinghe i wsp. 2015). Niektóre szczepy F. crookwellense mogą wytwarzać także fuzarenon $\mathrm{X}$, aurofuzarynę oraz beauwerycynę (Christ i wsp. 2011).
Celem pracy było określenie wpływu inokulacji wiech przez $F$. crookwellense na wielkość plonu oraz poziom zanieczyszczenia ziarna owsa mikotoksynami, a także wskazanie różnic $\mathrm{w}$ podatności wybranych genotypów na porażenie przez tego patogena.

\section{Materiały i metody / Materials and methods}

Badania przeprowadzono w latach 2014-2015, na polach doświadczalnych w południowo-wschodniej Polsce, w okolicach Zamościa. Objęto nimi 9 genotypów owsa, które zostały wytypowane przez hodowców i są przygotowywane dla praktyki rolniczej (tab. 1). Szkodliwość $F$. crookwellense dla owsa określono na podstawie ścisłego doświadczenia polowego ze sztucznym zakażaniem wiech w fazie kwitnienia. Chorobotwórczość szczepu $F$. crookwellense $\mathrm{nr} 72$, użytego do inokulacji określono metodą Mishry i Behra (1976). Sposób zakażania w polu był taki sam, jak we wcześniejszych badaniach owsa (Kiecana i wsp. 2012). Do inokulacji użyto zawiesinę konidiów F. crookwellense $\mathrm{nr} 72$, o zagęszczeniu $5 \times 10^{5}$ zarodników na $1 \mathrm{ml}$. Rośliny, których wiechy sztucznie zakażano wzrastały na poletkach doświadczalnych, o powierzchni $10 \mathrm{~m}^{2}$. Wokół poletek znajdowały się jednometrowe pasy ochronne oraz $40 \mathrm{~cm}$ ścieżki. Inokulację wiech przeprowadzono w fazie kwitnienia (65 w skali Zadoksa), materiałem infekcyjnym zakażano po 100 wiech każdego genotypu owsa, uznając za jedno powtórzenie 25 wiech. Wiechy z kombinacji kontrolnej opryskiwano tylko wodą destylowaną.

W fazie dojrzałości pełnej ziarna, wiechy zainokulowane i kontrolne zebrano, a następnie wydzielono ziarniaki i określono: liczbę ziarniaków w wiesze $(4 \times 10$ wiech $)$, plon ziarna z 10 wiech (w 4 powtórzeniach) oraz masę

Tabela 1. Wpływ sztucznego zakażania wiech owsa przez Fusarium crookwellense na liczbę ziarniaków w wiesze, plon ziarna z 10 wiech oraz mase 1000 ziaren (MTZ)

Table 1. Effect of artificial infection of oat panicles with Fusarium crookwellense on the number of grain per panicle, grain yield per 10 panicles and 1000 grain weight

\begin{tabular}{|c|c|c|c|c|c|c|c|c|c|c|c|c|}
\hline \multirow{3}{*}{$\begin{array}{c}\text { Genotypy owsa } \\
\text { Genotypes } \\
\text { of oat }\end{array}$} & \multicolumn{4}{|c|}{$\begin{array}{l}\text { Liczba ziarniaków w wiesze } \\
\text { Number of grain per panicle }\end{array}$} & \multicolumn{4}{|c|}{$\begin{array}{c}\text { Plon ziarna z } 10 \text { wiech - Grain yield } \\
\text { from } 10 \text { panicles [g] }\end{array}$} & \multicolumn{4}{|c|}{$\begin{array}{c}\text { Masa } 1000 \text { ziaren - } 1000 \text { grain weight } \\
{[\mathrm{g}]}\end{array}$} \\
\hline & \multicolumn{2}{|c|}{2014} & \multicolumn{2}{|c|}{2015} & \multicolumn{2}{|c|}{2014} & \multicolumn{2}{|c|}{2015} & \multicolumn{2}{|c|}{2014} & \multicolumn{2}{|c|}{2015} \\
\hline & F. cr. & K & F. cr. & K & F. cr. & $\mathrm{K}$ & F. cr. & $\mathrm{K}$ & F. cr. & $\mathrm{K}$ & F. cr. & $\mathrm{K}$ \\
\hline DC 060 & $82,87^{*}$ & 10657 & $86,4^{*}$ & 108,6 & $23,02 *$ & 30,83 & $29,46^{*}$ & 39,24 & 27,83 & & 34,00 & 36,00 \\
\hline DC07116-11/2 & $50,77^{*}$ & 67,92 & $63,9^{*}$ & 86,4 & $16,87^{*}$ & 22,48 & $24,81 *$ & 34,43 & 33,21 & & 38,31 & 39,88 \\
\hline DC 14-8 & $4,30 *$ & 79,60 & $54,9^{*}$ & 80,4 & $17,14 *$ & 25,00 & $21,84^{*}$ & 27,73 & 31,68 & 31, & 32,56 & 34,61 \\
\hline POB $4109 / 10$ & $33,00 *$ & 65,40 & $58,5^{*}$ & 84,8 & $9,39 *$ & 23,67 & $22,05^{*}$ & 30,75 & $28,63^{*}$ & 36,25 & 36,00 & 38,81 \\
\hline POB $6020 / 10$ & 68,95 & 73,40 & $80,6^{*}$ & 93,5 & 17,82 & 21,52 & & 33,04 & $25,81^{*}$ & & 34,63 & 35,38 \\
\hline POB 961-1344/13 & $74,75^{*}$ & 102,62 & $66,6^{*}$ & 86,5 & $17,91^{*}$ & 29,25 & $23,37 *$ & 33,31 & $23,81^{*}$ & 29,13 & $34,50 *$ & 38,50 \\
\hline STH 1.230 & $43,25^{*}$ & 74,20 & $63,5^{*}$ & 81,6 & $10,69 *$ & 25,30 & $20,78^{*}$ & 27,5 & $24,50 *$ & 33,81 & 32,50 & 33,69 \\
\hline STH 2.388 & $42,47 *$ & 72,45 & $68,7^{*}$ & 90,0 & $12,75^{*}$ & 22,98 & $24,21^{*}$ & 32,32 & 29,88 & 32,00 & 34,69 & 35,88 \\
\hline Denar & $42,35^{*}$ & 70,25 & 68,88 & 70,00 & $11,00^{*}$ & 22,18 & 26,98 & 29,50 & $25,69^{*}$ & 31,69 & $36,75^{*}$ & 42,19 \\
\hline Średnia - Mean & 54,75 & 79,16 & 68,00 & 86,87 & 15,18 & 24,80 & 24,96 & 31,98 & 27,89 & 32,02 & 34,88 & 37,22 \\
\hline
\end{tabular}

*średnie w poszczególnych latach różnią się istotnie w porównaniu do kontroli, przy p $\leq 0,05$ - compared to the control, the means differ significantly in the following years at $\mathrm{p} \leq 0.05$

F. cr. - Fusarium crookwellense, $\mathrm{K}$ - kontrola - control 
1000 ziaren. Uzyskane wyniki opracowano statystycznie wykorzystując półprzedziały ufności T-Tukeya. Najmniejsze istotne różnice obliczono dla poziomu istotności $\alpha=0,05$ (Żuk 1989).

Analizę zawartości mikotoksyn w ziarnie pochodzącym $\mathrm{z}$ wiech inokulowanych $F$. crookwellense przeprowadzono w Katedrze Chemii Uniwersytetu Przyrodniczego w Poznaniu. Oznaczanie trichotecenów z grupy B przeprowadzono po wcześniejszej ekstrakcji analizowanych związków acetonitryl : woda $(82: 18, \mathrm{v} / \mathrm{v})$ oraz oczyszczaniu metodą ekstrakcji do fazy stałej. Trichoteceny grupy B analizowano jako pochodne trimetylosililowe. Rozdział chromatograficzny oraz analiza prowadzona była oddzielnie za pomocą chromatografu gazowego (Hewlett Packard 6890) na kolumnie kapilarnej (HP-5MS, 0,25 mm $\times 30 \mathrm{~m}$ ) sprzężonego $\mathrm{z}$ detektorem masowym (Hewlett Packard 5972 A). Celem potwierdzenia obecności $\mathrm{W}$ próbie oznaczanych toksyn wykonana została analiza w pełnym zakresie mas (od 100-700 amu). Otrzymane wyniki poddano obróbce w programie Chem Station. Ziarno badanych genotypów na zawartość zearalenonu poddano ekstrakcji i po przesączeniu poddano procesowi oczyszczania na kolumienkach powinowactwa immunochemicznego firmy Vicam ${ }^{\circledR}$. Identyfikacja jakościowa i ilościowa zearalenonu została wykonana metodą wysokosprawnej chromatografii cieczowej (HPLC - high-performance liquid chromatography) z zastosowaniem aparatu Waters 2695, z zestawem detektorów Multi Fluorescence Detector Waters 2475, Photodiode Array Detector Waters 2996 oraz kolumną C18 Nova Pak 3,9 × $150 \mathrm{~mm}$. Fazę nośną stanowiła mieszanina rozpuszczalników - acetonitryl : woda : metanol $(46: 46: 8, \mathrm{v} / \mathrm{v} / \mathrm{v})$, rozdział został dokonany przy przepływie $0,5 \mathrm{ml} / \mathrm{min}$. i limicie detekcji $0,3 \mathrm{ng} / \mathrm{g}$.

\section{Wyniki i dyskusja / Results and discussion}

Do badań różnych aspektów fuzariozy kłosów i wiech dobiera się najbardziej skuteczne metody inokulacji (Kiecana 1994; Christ i wsp. 2011). W przedstawionych badaniach, wzorując się na przeprowadzanych wcześniej testach przez Mielniczuk i wsp. (2004), wiechy opryskiwano zawiesiną makrokonidiów $F$. crookwellense, uznając ten sposób za najbardziej odpowiadający naturalnej infekcji. Sztuczne zakażanie wiech przez $F$. crookwellense przy zastosowaniu opisanej metody okazało się skuteczne. $\mathrm{Na}$ wiechach inokulowanych wystąpiły objawy fuzariozy typowe dla naturalnej infekcji, przy czym na większej liczbie kłosków. Na plewach i plewkach obserwowano pomarańczowo-różowe sporodochia $\mathrm{z}$ zarodnikami konidialnymi. Z przeprowadzonych testów w warunkach doświadczenia polowego wynika, że zakażenie wiech przez $F$. crookwellense w fazie kwitnienia wpływa na zmniejszenie liczby ziarniaków, w mniejszym stopniu zaś na słabsze wykształcenie ziarna w wiesze. W 2014 r. istotne różnice w liczbie ziarniaków w wiesze oraz w plonie ziarna, w porównaniu do kontroli zanotowano u 8 genotypów owsa, wyjątek stanowił ród hodowlany POB 6020/10, zaś w 2015 r. istotnej obniżki liczby ziarniaków w wiesze oraz $\mathrm{w}$ plonie ziarna nie zanotowano w przypadku odmiany Denar, istotnej redukcji plonu $\mathrm{w}$ tym roku badań nie stwierdzono również u rodu hodowlanego POB 6020/10 (tab. 1). Badane genotypy owsa charakteryzowały się zróżnicowaną podatnością na porażenie wiech przez $F$. crookwellense, podobnie jak we wcześniejszych badaniach tego zboża (Mielniczuk i wsp. 2004). Obniżka liczby ziarniaków w wiesze w latach 2014 i 2015 wynosiła odpowiednio od 6,1 (POB 6020/10) do 49,5\% (POB 4109/10) i od 1,6 (Denar) do $31,7 \%$ (DC14-8) i różniła się istotnie u poszczególnych genotypów (rys. 1, 2). Ubytek plonu ziarna w porównaniu do kontroli był także zróżnicowany statystycznie i wynosił w 2014 r. od 17,2 (POB 6020/10) do $60,3 \%$ (POB 4109/10) oraz od 5,7 (POB 6020/10) do 29,8\% (POB 961-1344/13) w 2015 r. (rys. 1, 2). Średnia obniżka plonu ziarna w wyniku porażenia wiech przez $F$. crookwellense w 2014 roku wynosiła 38,96\% (rys. 1) i była wyższa aniżeli w badaniach owsa przeprowadzonych w latach 1996-1998 (Mielniczuk i wsp. 2004), natomiast w 2015 r. zanotowano 21,76\% redukcję plonu ziarna (rys. 2). Badania przeprowadzone w Kanadzie także wykazały znaczną agresywność sześciu izolatów $F$. crookwellense $\mathrm{w}$ stosunku do kłosów analizowanych genotypów pszenicy (Xue i wsp. 2004). Stwierdzono również, że sztuczne zakażanie wiech przez $F$. crookwellense wpłynęło istotnie na obniżkę masy 1000 ziaren w przypadku 5 genotypów owsa w 2014 r. oraz w przypadku 2 genotypów owsa w roku 2015 (tab. 1). Średnia obniżka MTZ dla wszystkich analizowanych genotypów owsa wynosiła $12,72 \%$ w 2014 r. i 6,02\% w 2015 r. (rys. 1, 2). Gatunek ten w warunkach sztucznego zakażania kłosów jęczmienia jarego spowodował większą obniżkę masy tysiąca ziaren, wynoszącą aż $52 \%$, przy czym udział porażonych ziarniaków wynosił 42\% (Perkowski i Kiecana 1998).

Analiza chemiczna ziarniaków pochodzących $\mathrm{z}$ wiech inokulowanych $F$. crookwellense w latach 2014 i 2015 potwierdziła zdolność tego gatunku do produkcji związków trichotecenowych $\mathrm{z}$ grupy $\mathrm{B}$, głównie niwalenolu, deoksyniwalenolu i fuzarenonu X (Perkowski i Kiecana 1998; Mielniczuk i wsp. 2004; Christ i wsp. 2011; Malihipour i wsp. 2012; Amarasinghe i wsp. 2015). Badany szczep $F$. crookwellense $\mathrm{nr} 72$ w największych ilościach wytwarzał niwalenol, średnie stężenie tego metabolitu w 2014 r. wynosiło 1,764 mg/kg, zaś w 2015 r. $0,085 \mathrm{mg} / \mathrm{kg}$ (tab. 2) i było niższe, aniżeli we wcześniejszych badaniach polowych jęczmienia i owsa (Perkowski i Kiecana 1998; Mielniczuk i wsp. 2004). Natomiast w badaniach Christ i wsp. (2011), szczep O $45 F$. cerealis wytwarzał w ziarnie pszenicy znacznie mniejsze ilości niwalenolu. Związek ten jest bardziej toksyczny dla zwierząt aniżeli DON, pomimo tego dotychczas nie ustalono dopuszczalnego poziomu zanieczyszczenia ziarna zbóż NIV (Amarasinghe i wsp. 2015). W ziarnie analizowanych genotypów owsa stwierdzono także obecność deoksyniwalenolu oraz fuzarenonu X. Średnia zawartość DON w ziarnie owsa wynosiła $0,050 \mathrm{mg} / \mathrm{kg}$ w $2014 \mathrm{r}$. i $0,027 \mathrm{mg} / \mathrm{kg}$ w 2015 r. i w przypadku żadnego z analizowanych genotypów nie przekraczała dopuszczalnego poziomu określonego w Rozporządzeniu Unii Europejskiej dla nieprzetworzonego ziarna owsa, czyli $1750 \mu \mathrm{g} / \mathrm{kg}$ (Rozporządzenie Komisji 2006). Znacznie większe ilości deoksyniwalenolu stwierdzano w ziarnie zbóż porażonym przez gatunek F. culmorum (Logrieco i wsp. 2003; Goliński i wsp. 2010). 


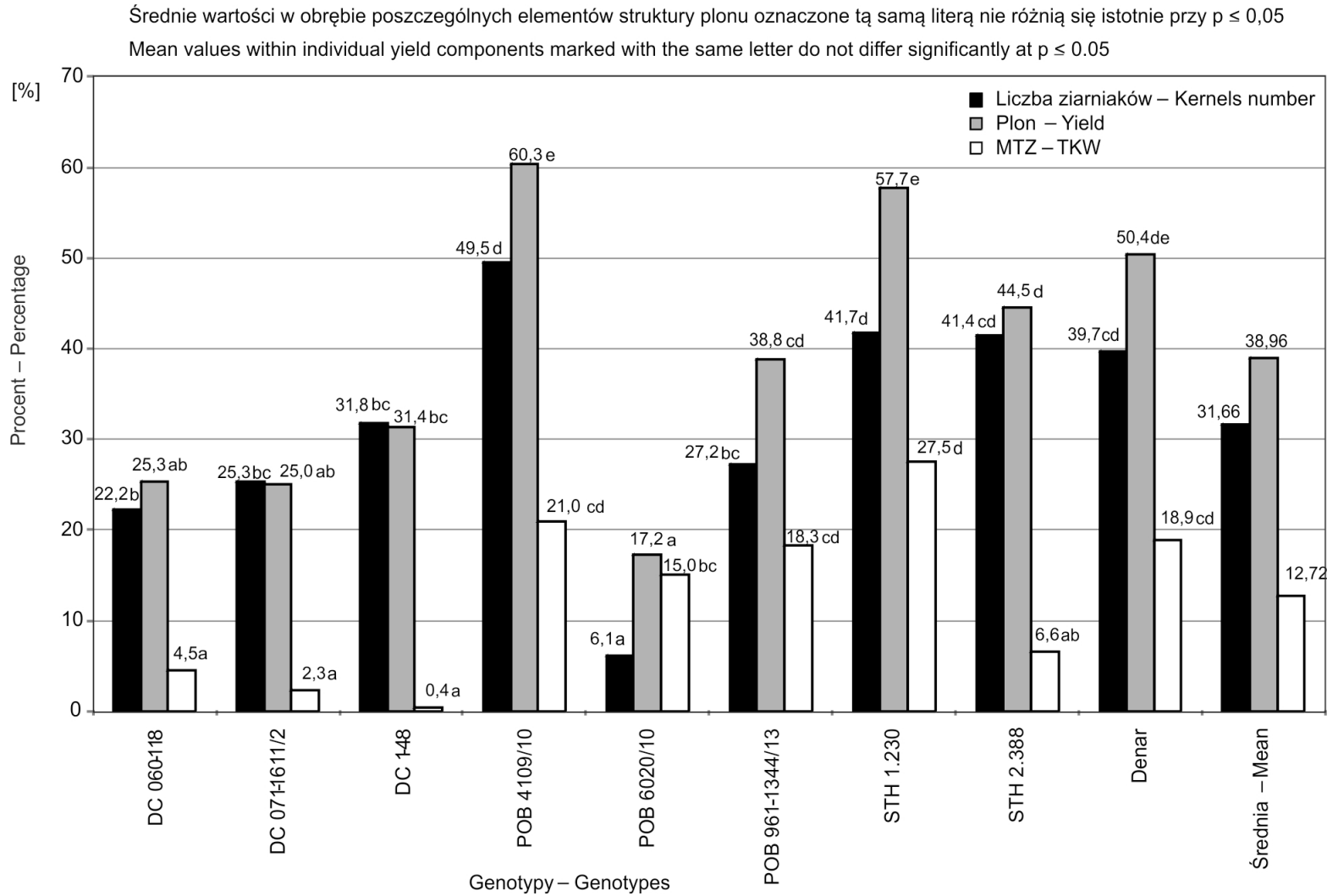

Rys. 1. Redukcja liczby ziarniaków w wiesze, plonu ziarna i masy 1000 ziaren po inokulacji wiech przez Fusarium crookwellense w 2014 r.

Fig. 1. Reduction in the number of grain per panicle, grain yield and 1000 grain weight after oat panicles inoculation with Fusarium crookwellense in 2014

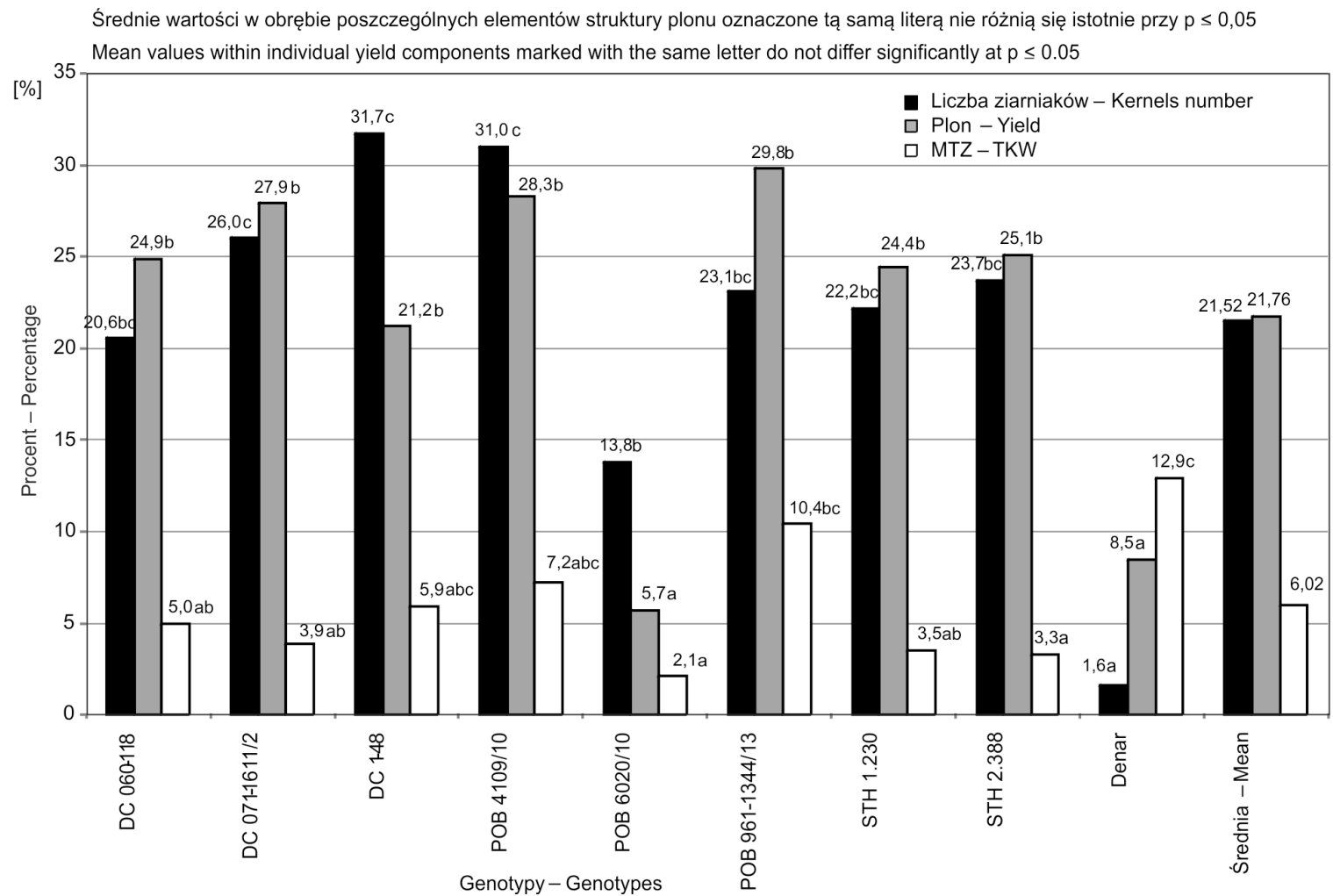

Rys. 2. Redukcja liczby ziarniaków w wiesze, plonu ziarna i masy 1000 ziaren po inokulacji wiech przez Fusarium crookwellense w $2015 \mathrm{r}$.

Fig. 2. Reduction in the number of grain per panicle, grain yield and 1000 grain weight after oat panicles inoculation with Fusarium crookwellense in 2015 
Tabela 2.Zawartość mikotoksyn $\mathrm{w}$ ziarnie owsa uzyskanym $\mathrm{z}$ wiech sztucznie zakażanych przez Fusarium crookwellense w 2014 i 2015 r.

Table 2. Content of mycotoxins in oat grain after panicles inoculation with Fusarium crookwellense in the years 2014 and 2015

\begin{tabular}{|c|c|c|c|c|c|c|c|c|c|c|}
\hline \multirow[t]{2}{*}{$\begin{array}{l}\text { Genotypy owsa } \\
\text { Genotypes of oat }\end{array}$} & \multicolumn{2}{|c|}{$\begin{array}{c}\text { Deoksyniwalenol } \\
\text { Deoxynivalenol } \\
(\mathrm{DON}) \\
{[\mathrm{mg} / \mathrm{kg}]}\end{array}$} & \multicolumn{2}{|c|}{$\begin{array}{c}3-\mathrm{Ac} \text { DON } \\
{[\mathrm{mg} / \mathrm{kg}]}\end{array}$} & \multicolumn{2}{|c|}{$\begin{array}{c}\text { Niwalenol } \\
\text { Nivalenol } \\
{[\mathrm{mg} / \mathrm{kg}]}\end{array}$} & \multicolumn{2}{|c|}{$\begin{array}{c}\text { Fuzarenon X } \\
\text { Fusarenone } X \\
{[\mathrm{mg} / \mathrm{kg}]}\end{array}$} & \multicolumn{2}{|c|}{$\begin{array}{c}\text { Zearalenon } \\
\text { Zearalenone } \\
{[\mu \mathrm{g} / \mathrm{kg}]}\end{array}$} \\
\hline & 2014 & 2015 & 2014 & 2015 & 2014 & 2015 & 2014 & 2015 & 2014 & 2015 \\
\hline DC 06011-8 & 0,032 & 0,113 & 0,017 & 0,010 & 2,285 & 0,384 & 0,089 & 0,021 & 0 & 0,005 \\
\hline DC07116-11/2 & 0,010 & 0,016 & 0,016 & 0,009 & 1,457 & 0,209 & 0,000 & 0,012 & 0 & 0,001 \\
\hline DC $14-8$ & 0,012 & 0,031 & 0,019 & 0,009 & 0,748 & 0,041 & 0,025 & 0,012 & 0 & 0,005 \\
\hline POB 4109/10 & 0,036 & 0,009 & 0,000 & 0,009 & 0,482 & 0,007 & 0,013 & 0,011 & 0,311 & 0,002 \\
\hline POB $6020 / 10$ & 0,049 & 0,035 & 0,024 & 0,009 & 2,341 & 0,035 & 0,049 & 0,012 & 0 & 0,003 \\
\hline POB 961-1344/13 & 0,012 & 0,012 & 0,013 & 0,009 & 3,256 & 0,044 & 0,172 & 0,011 & 0 & 0,005 \\
\hline STH 1.230 & 0,205 & 0,009 & 0,016 & 0,008 & 3,144 & 0,020 & 0,162 & 0,011 & 0 & 0,000 \\
\hline STH 2.388 & 0,016 & 0,009 & 0,024 & 0,009 & 1,013 & 0,015 & 0,049 & 0,012 & 0 & 0,001 \\
\hline Denar & 0,063 & 0,009 & 0,023 & 0,009 & 1,149 & 0,009 & 0,031 & 0,11 & 0 & 0,001 \\
\hline Średnia - Mean & 0,050 & 0,027 & 0,017 & 0,009 & 1,764 & 0,085 & 0,066 & 0,024 & 0,00003 & 0,003 \\
\hline
\end{tabular}

Tabela 3. Temperatura powietrza i opady w sezonach wegetacji owsa 2014 i 2015 w okolicach Zamościa

Table 3. Air temperature and rainfall in the Zamość region during the growing seasons of oat in 2014 and 2015

\begin{tabular}{l|c|c|c|c|c|c}
\hline \multirow{2}{*}{$\begin{array}{c}\text { Miesiąc } \\
\text { Month }\end{array}$} & \multicolumn{2}{|c|}{$\begin{array}{c}\text { Średnie wieloletnie } \\
\text { Long-term mean } \\
(1971-2000)\end{array}$} & \multicolumn{2}{c|}{$\begin{array}{c}\text { Odchylenie temperatury } \\
\text { powietrza } \\
\text { Deviation of air temperature } \\
{\left[{ }^{\circ} \mathrm{C}\right]}\end{array}$} & \multicolumn{2}{c}{$\begin{array}{c}\text { Procent normy opadów } \\
\text { Percentage of rainfall } \\
{[\%]}\end{array}$} \\
\cline { 2 - 8 } & $\begin{array}{c}\text { temperatura powietrza } \\
\text { air temperatures } \\
{\left[{ }^{\circ} \mathrm{C}\right]}\end{array}$ & $\begin{array}{c}\text { opady } \\
\text { rainfall } \\
{[\mathrm{mm}]}\end{array}$ & 2014 & 2015 & 2014 & 2015 \\
\hline Kwiecień - April & 9 & 40 & $+0,4$ & $-1,5$ & 115 & 100 \\
\hline Maj- May & 15 & 75 & $+1,2$ & $-2,0$ & 280 & 153 \\
\hline Czerwiec - June & 17 & 110 & $-1,0$ & 0,0 & 77 & 50 \\
\hline Lipiec- July & 18 & 90 & $+2,5$ & $+2,0$ & 111 & 72 \\
\hline Sierpień - August & 17 & 60 & $+0,3$ & $+4,5$ & 163 & 8 \\
\hline
\end{tabular}

Deoksyniwalenol i jego acetylowe pochodne należą do najczęściej spotykanych trichotecenów w ziarnie zbóż oraz w paszach i produktach żywnościowych, a długotrwałe przyjmowanie nawet niewielkich ilości DON powoduje między innymi: podrażnienia skóry, zaburzenia nerwowe i osłabienie systemu odpornościowego (Płażek 2011). Średnie stężenie fuzarenonu $\mathrm{X}$ w ziarnie analizowanych genotypów owsa wynosiło odpowiednio $0,066 \mathrm{mg} / \mathrm{kg}$ i $0,024 \mathrm{mg} / \mathrm{kg}$ (tab. 2). Podobnie, jak w przypadku sztucznego zakażania kłosów jęczmienia jarego przez F. crookwellense (Perkowski i Kiecana 1998), w ziarnie owsa po inokulacji przez ten gatunek grzyba stwierdzono obecność 3-Ac DON (tab. 2). Ponadto badany szczep F. crookwellense $\mathrm{nr}$ 72, produkował $\mathrm{w}$ ziarnie niektórych genotypów owsa nieznaczne ilości zearalenonu (tab. 2), uważanego za charakterystyczny dla tego gatunku grzyba (Bottalico i Perrone 2002; Christ i wsp. 2011).

Uzyskane wyniki potwierdzają wpływ warunków pogodowych na porażenie wiech przez Fusarium spp. oraz zawartość mikotoksyn w ziarnie (Xu i wsp. 2008; Góral i wsp. 2012). Przebieg pogody w okresie wegetacji owsa w 2014 roku, charakteryzujący się większą ilością opadów, aniżeli w 2015 roku (tab. 3), okazał się bardziej sprzyjający dla rozwoju fuzariozy wiech owsa powodowanej przez Fusarium spp., w tym F. crookwellense (Kiecana i wsp. 2012).

\section{Wnioski / Conclusions}

1. Wielkość plonu rodów hodowlanych owsa była zróżnicowana, a w przypadku rodów POB 4109/10 i STH 1.230 porażonych przez $F$. crookwellense była najniższa. Najmniejszy wpływ inokulacji wiech na plon owsa stwierdzono u rodu hodowlanego POB 6020/10.

2. Obecność metabolitów $F$. crookwellense wpływała na gorszą jakość uzyskanego plonu ziarna.

3. Poziom zanieczyszczenia ziarna owsa mikotoksynami był zróżnicowany u poszczególnych genotypów. Zawartość deoksyniwalenolu oraz zearalenonu w ziarnie owsa nie przekraczała norm dopuszczalnych przez Unię Europejską. 


\section{Literatura / References}

Amarasinghe C.C., Tittlemier S.A., Fernando W.G.D. 2015. Nivalenol-producing Fusarium cerealis associated with fusarium head blight in winter wheat in Manitoba. Canadian Plant Pathology 64 (4): 988-995. DOI: 10.1111/ppa.12329.

Bottalico A., Perrone G. 2002. Toxigenic Fusarium species and mycotoxins associated with head blight in small-grain cereals in Europe. European Journal of Plant Pathology 108 (7): 611-624. DOI: 10.1023/A:1020635214971.

Castañares E., Dinolofo M.I., Moreno M.V., Berón C., Stenglein A.S. 2013. Fusarium cerealis associated with barley seeds in Argentina. Journal of Phytopathology 161: 586-589. DOI: 10.1111/jph.12097.

Christ D.S., Gödecke R., von Tiedemann A., Varrelmann M. 2011. Pathogenicity, symptom development, and mycotoxin formation in wheat by Fusarium species ferquently isolated from sugar beet. Phytopathology 101 (11): 1338-1345. DOI: 10.1094/PHYTO-0111-0003.

Goliński P., Waśkiewicz A., Wiśniewska H., Kiecana I., Mielniczuk E., Gromadzka M., Kostecki M., Bocianowski J., Rymaniak E. 2010. Reaction of winter wheat (Triticum aestivum L.) cultivars to infection with Fusarium spp. mycotoxins contamination in grain and chaff. Food Additives \& Contaminants: Part A 27 (7): 1015-1024. DOI: 10.1080/19440041003702208.

Góral T., Ochodzki P., Walentyn-Góral D., Nielsen L.K., Justesen A.F., Jørgensen L.N. 2012. Wpływ przedplonu oraz warunków pogodowych na porażenie kłosów przez grzyby z rodzaju Fusarium oraz zawartość mikotoksyn w ziarnie. [Effect of pre-crop and weather conditions on infection of heads of spring wheat with Fusarium fungi and content of mycotoxins in grain]. Biuletyn Instytutu Hodowli i Aklimatyzacji Roślin 265: 11-21.

Kiecana I. 1994. Badania nad fuzariozą kłosów jęczmienia jarego (Hordeum vulgare L.) z uwzględnieniem podatności odmian i zawartości mikotoksyn w ziarnie. [Investigations on Fusarium head blight of spring barley (Hordeum vulgare L.) concerning susceptibility of cultivars and mycotoxins accumulation in kernels]. Rozprawy Naukowe. Akademia Rolnicza, Lublin 161, 49 ss.

Kiecana I., Mielniczuk E. 2010. Fusarium head blight of rye (Secale cereale L.). Acta Agrobotanica 63 (1): $129-135$.

Kiecana I., Cegiełko M., Mielniczuk E., Perkowski J. 2012. The occurrence of Fusarium poae (Peck) Wollenw. on oat (Avena sativa L.) panicles and its harmfulness. Acta Agrobotanica 65 (4): 169-178. DOI: 10.5586/aa.2012.035.

Lauren D.R., Di Menna M.E. 1999. Fusaria and Fusarium mycotoxins in leaves and ears of maize plants. II. A time course study made in the Waikato region, New Zealand, in 1997. New Zealand Journal of Crop and Horticultural Science 27: 215-223.

Logrieco A., Bottalico A., Mulé G., Moretti A., Perrone G. 2003. Epidemiology of toxigenic fungi and their associated mycotoxins for some mediterranean crops. European Journal of Plant Pathology 109 (7): 645-667. DOI: 10.1023/A:1026033021542.

Malihipour A., Gilbert J., Piercey-Normore M., Cloutier S. 2012. Molecular phylogenetic analysis, trichothecene chemotype patterns, and variation in aggressiveness of Fusarium isolates causing head blight in wheat. Plant Diseases 96 (7): $1016-1025$. http://dx.doi.org/10.1094/ PDIS-10-11-0866-RE.

Martinelli J.A., Chaves M.S., Graichen F.A.S., Federizzi L.C., Dresch L.F. 2014. Impact of fusarium head blight in reducing the weight of oat grains. Journal of Agricultural Science 6 (5): 188-198. DOI: 10.5539/jas.v6n5p188.

Mielniczuk E. 2001. The occurrence of Fusarium spp. on panicles of oat (Avena sativa L.). Journal of Plant Protection Research 41 (2): 173-180.

Mielniczuk E., Kiecana I., Perkowski J. 2004. Susceptibility of oat genotypes of Fusarium crookwellense Burgess, Nelson and Toussoun infection and mycotoxin accumulation in kernels. Biologia, Bratislava 59 (6): 809-816.

Mishra C.B.P., Behr L. 1976. Der Einfluss von Kulturfiltraten Fusarium culmorum (W.G. Sm.) Sacc., Fusarium avenaceum (Fr.) Sacc. und Fusarium nivale (Fr.) Ces., Griphosphaeria nivalis Müller et v. Arx auf die Keimung des Weizen. Archiv für Phytopathologie und Pflanzenschutz 12 (6): 373-377.

Nielsen L.K., Jensen J.D., Nielsen G.C., Jensen J.E., Spliid N.H., Thomsen I.K., Justesen A.F., Collinge D.B., Jørgensen L.N. 2011. Fusarium head blight of cereals in Denmark: species complex and related mycotoxins. Phytopathology 101 (8): 960-969. DOI: 10.1094/PHYTO-07-10-0188.

Perkowski J., Kiecana I. 1998. Biosynteza toksyn fuzaryjnych w ziarnie jęczmienia jarego (Hordeum vulgare L.) po inokulacji kłosów Fusarium crookwellense Burgess, Nelson, Toussoun, Fusarium culmorum (W.G. Sm.) Sacc. i Fusarium graminearum Schwabe. [Biosynthesis of Fusarium toxins in kernels of spring barley (Hordeum vulgare L.) inoculated with Fusarium crookwellense Burgess, Nelson, Toussoun, Fusarium culmorum (W.G. Sm.) Sacc. and Fusarium graminearum Schwabe]. Biuletyn Instytutu Hodowli i Aklimatyzacji Roślin 207: 69-80.

Płażek A. 2011. Patofizjologia roślin. Wydawnictwo Uniwersytetu Rolniczego w Krakowie, 139 ss.

Rozporządzenie Komisji (WE) nr 1881/2006 z dnia 19 grudnia 2006 r. ustalające najwyższe dopuszczalne poziomy niektórych zanieczyszczeń w środkach spożywczych (Dz. Urz. UE L 364/5 z dnia 20.12.2006 r.).

Sugiura Y., Saito H., Tanaka T., Ichinoe M., Ueno Y. 1994. Fusarium crookwellense, a newly isolated fungus from wheat in Japan: Its mycotoxin production and pathogenicity to wheat and barley. Mycoscience 35 (1): 77-82. DOI: 10.1007/BF02268532.

Šrobarová A., Šliková S., Šudyová V. 2008. Diversity of the Fusarium species associated with head and seedling blight on wheat in Slovakia. Biologia, Bratislava 63 (3): 332-337. DOI: 10.2478/s11756-008-0050-y.

Tekauz A., McCallum B., Ames N., Mitchell Fetch J. 2004. Fusarium head blight of oat - current status in western Canada. Canadian Journal of Plant Pathology 26 (4): 473-479. http://dx.doi.org/10.1080/07060660409507167.

Xu X.M., Nicholson P., Thomsett M.A., Simpson D., Cooke B.M., Doohan F.M., Brennan J., Monghan S., Moretti A., Mule G., Hornok L., Beki E., Tatnell J., Ritinei A. 2008. Relationship between the fungal complex causing Fusarium head blight of wheat and environmental conditions. Phytopathology 98 (1): 69-78.

Xue A.G., Armstrong K.C., Voldeng H.D., Fedak G., Babcock C. 2004. Comparative aggressiveness of isolates of Fusarium spp. causing head blight on wheat in Canada. Canadian Journal of Plant Pathology 26 (1): 81-88. http://dx.doi.org/10.1080/ 07060660409507117.

Zhang H., Chen W.Q., Xu J., Xu J.S., Feng J. 2011. First report of Fusarium cerealis causing Fusarium head blight on barley in China. Plant Disease 95 (6), p. 774. http://dx.doi.org/10.1094/PDIS-12-10-0933.

Żuk B. 1989. Biometria stosowana. Wydawnictwo Naukowe PWN, Warszawa, 422 ss. 